\title{
Facilitators and Inhibitors in the Assimilation of Complex Information Systems
}

\author{
Anand Jeyaraj \\ Wright State University, Dayton, Ohio, USA \\ anand.jeyaraj@wright.edu
}

\begin{abstract}
Complex information systems may be viewed as systems that cut across functional boundaries within an organization and even organizational boundaries. These include enterprise resource planning (ERP) systems, supply chain management (SCM) systems, customer relationship management (CRM) systems, product lifecycle management (PLM) systems and business-tobusiness (B2B) systems. Such systems pose significant knowledge barriers for assimilation, require coordination with internal and external actors, and entail reengineering of both cross-functional and inter-organizational business processes. Moreover, organizations progress through various stages of assimilation such as initiation, experimentation, implementation, and routinization in assimilating complex systems.

An often-overlooked consideration when dealing with such systems is that organizations may not completely assimilate them and even abandon them midway through the assimilation process. Such stories are well-documented in the popular press (e.g., failed projects, cancelled contracts) but generally do not provide insightful explanations of the accompanying assimilation process. However, there is not much evidence in prior empirical literature as to how assimilation processes came together in real-world organizations or the differences in the assimilation processes between organizations that succeeded or failed when dealing with complex information systems.

Conceptualizing assimilation as a process by which organizations move from the initiation through the routinization stages, this research strives to uncover facilitators that enable an organization to move to the next stage and inhibitors that may force organizations to stay in the current stage or completely abandon the assimilation process. Employing a multiple case-study approach involving both successful and failed projects of different complex systems with data provided by key informants, this research aims to uncover usable knowledge for researchers and practitioners.
\end{abstract}

Keywords: Complex information systems, assimilation, stages, facilitators, inhibitors.

\section{Introduction}

Complex information systems include enterprise resource planning (ERP) systems, supply chain management (SCM) systems, customer relationship management (CRM) 
systems, product lifecycle management (PLM) systems, and business-to-business (B2B) systems (e.g. Wang et al. 2008). Such complex information systems may cut across functional boundaries within an organization or even organizational boundaries, pose significant knowledge barriers for assimilation, take considerable time for implementation, need coordination between internal and external actors of the organization, and require reengineering of cross-functional and inter-organizational business processes (Attewell 1992; Fichman and Kemerer 1999; Gallivan 2001; Roberts et al. 2012). Often times, organizations enlist the assistance of external consultants or other professionals to ensure the successful implementation and deployment of such complex information systems.

When dealing with complex information systems, organizations may not completely assimilate or routinize them and sometimes even abandon them midway through the assimilation process. Such stories are well-documented in the popular press (e.g., failed projects, cancelled contracts, abandoned implementations). Consider, for example, two high-profile cases. The United Kingdom government scrapped a $£ 12$ billion National Program for IT in 2011 that was aimed at providing electronic health records for citizens after having been in the works for more about 10 years (PCWorld 2011). The United States Air Force terminated the Expeditionary Combat Support System (ECSS) with its provider after more than 7 years of effort and costs totaling more than $\$ 1$ billion (IEEE Spectrum 2012). However, insightful explanations of the accompanying assimilation process in such implementations are often missingwhich are crucial for understanding why projects succeed or fail.

Conceptualizing assimilation as a process by which organizations move through various stages from initiation through routinization, this research strives to explain how and why the implementation of complex information systems may become unqualified successes or spectacular failures. Moreover, this research aims to uncover facilitators that enable an organization to move to the next stage in the assimilation process and inhibitors that may force organizations to remain in the current stage or even completely abandon the assimilation process.

\section{Assimilation}

Assimilation may be defined as the process by which organizations identify, adopt, and routinize complex information systems for their operations. Ettlie and Vellenga (1979) described six different stages of assimilation: awareness, interest, evaluation, trial, adoption, and implementation. Fichman and Kemerer (1997) and Fichman (2001) proposed six stages of assimilation: awareness, interest, evaluation/ trial, commitment, limited deployment, and general deployment - the evaluation and trial stages were combined into a single stage, while the implementation stage was split into the limited deployment and general deployment stages. Kwon and Zmud (1987), Cooper and Zmud (1990), and Gallivan (2001) argued for six stages of assimilation as well: initiation, adoption, adaptation, acceptance, routinization, and infusion. Rogers (1995) introduced five different stages of assimilation for organizations: agenda-setting, matching, redefining/ restructuring, clarifying, and routinizing. 
Figure 1 identifies the assimilation stages employed in this study, which have been formulated based on descriptions of assimilation in prior literature. These stages are designed to accommodate organizational activities from the early phases when the organization may evaluate its needs or identify opportunities for complex information systems to the late phases when the organization may routinize the usage of complex information systems for various business processes.

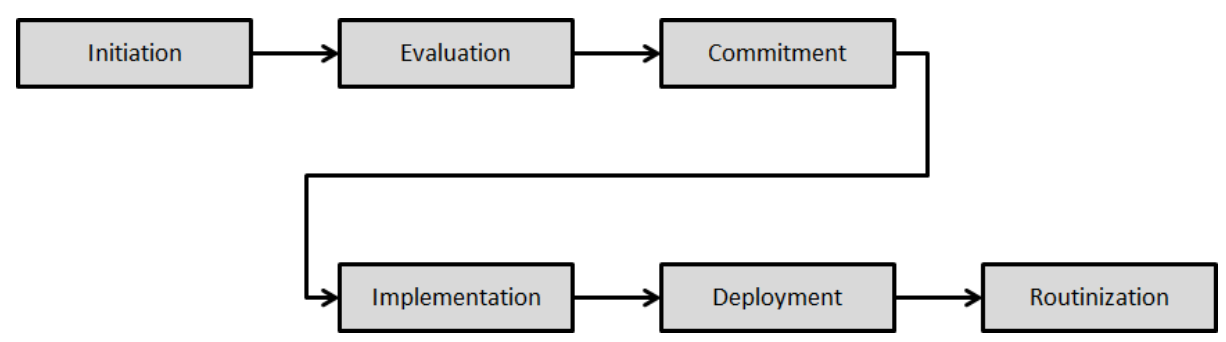

Fig. 1. Assimilation stages

\section{Methods}

This research employs a multiple case-study approach to examine the assimilation process at organizations that dealt with complex information systems. Multiple key informants knowledgeable of the organizations' assimilation activities are targeted for discussion. The interviews with key informants are semi-structured in that they deal with a specific set of broad questions on an interview guide but allow the informants to describe the assimilation process in as much detail as they possibly can in their own words consistent with how the process transpired within the organization. The interview guide includes questions that may elicit responses on how the organization initiated its journey with complex information systems, the sequence of activities that may have taken the organization through evaluation, commitment, commitment, implementation and deployment stages, and how it routinized the usage of complex information systems within its boundaries. The data analysis will involve two phases: a) a within-case analyses that illuminates the specific assimilation process within the organization and b) a cross-case analysis that identifies patterns in the assimilation processes across organizations. The combination of within-case and cross-case analyses would enable the extraction of facilitators and inhibitors that drive the assimilation of complex information systems by organizations. The research would provide usable knowledge on assimilation of complex information systems for both researchers and practitioners.

\section{References}

Attewell, P.: Technology diffusion and organizational learning: The case of business computing. Organization Science 3(1), 1-19 (1992)

Cooper, R.B., Zmud, R.W.: Information Technology Implementation Research: A Technological Diffusion Approach. Management Science 36(2), 123-139 (1990) 
Ettlie, J.E., Vellenga, D.B.: The Adoption Time Period for Some Transportation Innovations. Management Science 25(5), 429-443 (1979)

Fichman, R.G.: The Role of Aggregation in the Measurement of IT-Related Organizational Innovation, MIS Quarterly 25(4) (2001)

Fichman, R.G., Kemerer, C.F.: The Assimilation of Software Process Innovations: An Organizational Learning Perspective. Management Science 43(1), 1345-1363 (1997)

Fichman, R.G., Kemerer, C.F.: The illusory diffusion of innovation: An examination of assimilation gaps. Information Systems Research 10(3), 255-275 (1999)

Gallivan, M.J.: Organizational adoption and assimilation of complex technological innovations: development and application of a new framework. SIGMIS Database 32(3), 51-85 (2001)

IEEE Spectrum. US Air Force blows \$1 Billion on failed ERP Project (2012), http://spectrum.ieee.org/riskfactor/aerospace/military/ us-air-force-blows-1-billion-on-failed-erp-project, (accessed February 25, 2013)

Kwon, T.H., Zmud, R.W.: Unifying the Fragmented Models of Information Systems Implementation. In: Boland Jr., R.J., Hirschheim, R.A. (eds.) Critical Issues in Information Systems Research. John Wiley \& Sons, Ltd. (1987)

PCWorld. 10 biggest ERP software failures of 2011(2011), http://www.pcworld.com/article/246647/10_biggest_erp_software _failures_of_2011.html (accessed February 25, 2013)

Wang, W., Hsieh, J.J.P., Butler, J.E., Hsu, S.: Innovate with complex information technologies: A theoretical model and empirical examination. Journal of Computer Information Systems 49(1), 27-36 (2008)

Roberts, N., Galluch, P.S., Dinger, M., Grover, V.: Absorptive Capacity and Information Systems Research: Review, Synthesis, and Directions for Future Research. MIS Quarterly 36(2), 625-648 (2012)

Rogers, E.M.: Diffusion of Innovations. The Free Press, New York (1995) 